\title{
Prevalence of chest symptomatics of tuberculosis among diabetes patients in Udupi taluk
}

\author{
Swapnil Nimkar \\ United Nations Development Programme, Mysuru, Karnataka, India
}

\section{A R T I C L E I N F O}

\section{Keywords:}

Chest symptomatics

Diabetes Mellitus

Tuberculosis

\begin{abstract}
A B S T R A C T
Context: Diabetes is becoming prevalent dramatically in the Asian countries. In India, 15\% of tuberculosis (TB) cases are attributed to diabetes mellitus (DM).

Objectives: 1 . To determine the prevalence of chest symptomatics among diabetes patients in Udupi taluk. 2. To assess the factors associated with diabetes mellitus which might predispose to tuberculosis.

Methods and material: A cross-sectional study was done from March 2013 to Aug 2013. Convenience sampling was adopted. Interviews of 132 diabetes patients were conducted in Udupi taluk. Data was analyzed using descriptive and univariate analysis.

Results: The study revealed the prevalence of chest symptomatics of TB among diabetes patients as $10.6 \%$. In the study, $78.6 \%$ of subjects had history of cough associated with sputum. Approximately, two third of the chest symptomatics $(66.7 \%)$ reported that they were smoking for more than 25 years. The significant association of chest symptoms of TB was found with the factors such as; history of TB ( $\mathrm{p}=0.017)$, history of intermittent cough $(\mathrm{p}<0.0001)$, per capita income of the respondents $(\mathrm{p}=0.023)$ and total monthly family income of respondents $(\mathrm{p}=0.028)$.

Conclusions: Occurrence of chest symptoms elucidated poor socioeconomic conditions among respondents. History of intermittent cough and history of TB in the past, contributed as a major factor for predisposition to TB. It is recommended to design; feasible and cost effective, integrated public health care approach for bidirectional screening model within primary health care system in India.
\end{abstract}

\section{Introduction}

In the context of economic development, causal pathway of health issues progressed from infectious to non-infectious diseases, leading to increased burden on public health system. Sir William Osler (1892) described TB (Tuberculosis); as most universal scourge of human race. ${ }^{1}$ Susruta, the first Indian physician (600 A.D) addressed the link of diabetes and tuberculosis. ${ }^{2}$ In recent decades, tuberculosis incidence decreases in high income countries but remains high in the countries comprising of; high prevalence of malnutrition and HIV (Human Immunodeficiency Virus) as well as crowded slums situations. Currently, more than $80 \%$ of adults with diabetes live in low-income or middleincome countries, and diabetes generally presents at a younger age in these countries. ${ }^{3}$

Around $46 \%$ of diabetics are reckoned to be undiagnosed worldwide, and $84 \%$ of those undiagnosed, live in (LMICs) low and middleincome countries, where tuberculosis prevalence is high. ${ }^{4}$

The shift in the paradigm between the positive effect of reducing food insecurity in the world and the negative effects of increased obesity and diabetes prevalence, is considered as crucial element in TB epidemiology. ${ }^{5}$

Diabetes with TB represents intricate intersection between communicable and non-communicable diseases. The revised epidemiological targets in new global tuberculosis strategy are based on unprecedented decrease of tuberculosis incidence, from the present $2 \%$ per year to $10 \%$ per year globally, by 2025 . At the same time, the tuberculosis case fatality rate is expected to be halved from $15 \%$ to $6.5 \%$, by $2025^{6}$

At cellular level, T helper 1 cytokines play a crucial role in controlling mycobacterium infection. This cytokine response is observed less among diabetes patients. ${ }^{7}$ In this weak knee-jerk reaction, person does not get any symptom and cannot spread any infection to other people. Bacteria break out through the scar and cause reactivation of tuberculosis. ${ }^{8}$ The massive destruction of lung tissues precedes to present more cavities and exaggerated chest symptoms. In this scenario, Ketone bodies in the blood of diabetes patients provides favorable environment for reactivation of TB. It is also known, that diabetic autonomic neuropathy can lead to variation in basal airway tone which

E-mail address: nilmanipal@gmail.com. 
elicits vagal inhibitory response, causing reduced bronchial reactivity as well as bronchodilation; progressively, induce Lower Respiratory Tract Infection (LRTI). ${ }^{9}$ Apart from this, genetic studies have also shown the connection of genes with diabetes-tuberculosis co-morbidity. HK2 gene encodes for hexokinase 2 enzyme, which has a crucial role in aerobic glycolysis. The process of glycolysis provides energy to macrophages. So, abnormality of HK2 gene leads to impairment of macrophages activity. Eventually, it increases susceptibility to respiratory infections. Similarly, reduced expression of gene CD28, leads to lower the immune responses to $\mathrm{T}$ cell receptors on surface of $\mathrm{CD}$ cells and tends to decline the level of IL- 2 by activating T lymphocytes. ${ }^{10}$

Diabetes can create its adverse outcomes during management of TB as; hyperglycemia results in reduced bioavailability of Rifampicin ${ }^{11} \mathrm{DM}$ (Diabetes Mellites) might be responsible to increase the time of sputum conversion and it may develop the drug resistance as well. ${ }^{12}$ People with DM are more likely to fail anti-TB treatment and eventually; tend to die during treatment, compared to those without diabetes.

One third of the world population is currently infected with tuberculosis. India contributes one fifth of the global burden of tuberculosis. Prevalence of tuberculosis in India was 249 per 100000 in $2010 .^{13}$ About $70 \%$ of DM patients live in developing countries especially in South East Asian and Western pacific countries ${ }^{14}$ In 2011, India had 6.13 crore people living with diabetes with 983,000 deaths attributable to it (IDF 2011). Karnataka attributes approximately $11 \%$ of total diabetes patients in India. ${ }^{15}$

According to Millennium Development Goal (MDG) and Diabetes report, IDF, in India, 15\% tuberculosis is attributed to diabetes. ${ }^{16}$ Mexico emerged as a global leader in implementing collaborative efforts for diabetes-TB co-morbidity. ${ }^{17}$ People with diabetes are around 2.5 times more prone to develop TB (IDF Diabetic atlas, fifth edition). In India, there is a great need of addressing chest symptomatics of tuberculosis among diabetics; to render them towards enhanced passive case detection. This would contribute to early case detection, which is the principal strategy of tuberculosis control. The current study will turn out to be contemporary evidence for public health scientists.

Objectives of the study were to determine the prevalence of chest symptomatics of tuberculosis among diabetes patients in Udupi taluk and to assess the factors associated with diabetes which might predispose to tuberculosis.

\section{Material and methods}

Study design: Descriptive cross-sectional study was conducted from March 2013 to August 2013.

Setting: 'Random blood sugar (RBS) above normal level' was considered as the criteria for diagnosis of diabetes mellitus among normal individuals. The study involved the individuals who were already diagnosed for diabetes mellitus in government primary health care system in Udupi taluk.

Data collection method: Convenience sampling was adopted. Data was collected from sampled diabetic patients by doing survey in various identified sites in Udupi taluk.

List of all PHCs (Primary Health Centers) and CHCs (Community Health Centers) was obtained from District health and family welfare office, Udupi. Medical officers and health workers of respective PHCs were contacted and appointments were fixed with them. List of diagnosed diabetes patients was obtained from health workers of selected health care facility. Available addresses of diabetes patients were searched with the help of health workers to conduct survey. Before conducting interviews, health workers as well as respondents were oriented about the questions and method of conducting interview. A translated Kannada version of semi-structured questionnaire was prepared to conduct face to face interviews. Pilot study was done to validate the questionnaire. Modifications were done in questionnaire after pilot study. Apart from this, questionnaire was validated by research experts in Manipal University.
Table 1

Distribution of respondents according to age, sex and religion, DM status, duration of DM, DM treatment status $(\mathrm{N}=132)$.

\begin{tabular}{lll}
\hline Variables & & $\mathrm{N}(\%)$ \\
\hline Age (years) & $18-29$ & $1(0.8)$ \\
& $30-39$ & $8(6.1)$ \\
& $40-49$ & $22(16.7)$ \\
& $50-59$ & $34(25.8)$ \\
& $60-69$ & $42(31.8)$ \\
Sex & $70 \&$ above & $25(18.9)$ \\
Religion & Male & $68(51.5)$ \\
& Female & $64(48.5)$ \\
DM status & Hindu & $115(87.1)$ \\
& Muslim & $15(11.4)$ \\
Duration of diabetes & Christian & $2(1.5)$ \\
& IDDM & $10(7.6)$ \\
& NIDDM & $122(92.4)$ \\
DM treatment status & $<1$ year & $18(13.6)$ \\
& $1-5$ years & $71(53.8)$ \\
& $>5$ years & $43(32.6)$ \\
& Regular & $125(94.7)$ \\
\hline
\end{tabular}

$\mathrm{N}=$ Number

DM $=$ Diabetes Mellitus

IDDM $=$ Insulin Dependent Diabetes Mellitus

NIDDM $=$ Noninsulin Dependent Diabetes Mellitus

Inclusion criteria: 1 . Clinically diagnosed cases of diabetes mellitus 2. Subjects of age at least 18 years or above 3 . Respondents who gave written informed consent clearly.

Exclusion criteria: 1 . Seriously ill patients 2. Already diagnosed tuberculosis patients having history of diabetes mellitus.

Ethical clearance: The ethical clearance for the study was obtained from Institutional Ethics Committee, Manipal University. Permission was obtained from District Health and Family Welfare Office, Udupi to get technical support for the study. The patients were given brief information regarding study before conducting interviews. Written informed consent was obtained from all respondents.

Analysis: Data analysis was done with the help of statistical software SPSS (Statistical Package for the Social Sciences) version 15.00.

Case Definition: In the study, a person having cough since at least two weeks or more than two weeks; at the time of interview, is considered as a 'chest symptomatic'.

\section{Results}

Table 1 shows the distribution of diabetes patients according to age, sex and religion. Most of the respondents belonged to 60-69 years age group (31.8\%). The age group of 50-59 years constitutes $25.8 \%$ respondents. Majority of the participants in the study, were Hindus (87.1\%). Only $1.5 \%$ respondents were found to be Christians. Table 1 shows the distribution of the respondents according to DM status, duration of diabetes and treatment status. Around $92.4 \%$ patients indicated the pattern of having NIDDM (Non-insulin Dependent Diabetes Mellitus). Out of the total respondents, more than half of the respondents (53.8\%) were having history of diabetes for one to five years. The table shows the trend about treatment status which; denotes that most of the patients were taking treatment for diabetes, regularly (94.7\%). As shown in the Table 2, out of 25 respondents having cough, $44 \%$ respondents had cough associated with sputum. Apart from this, $20 \%$ of those respondents had history of chest pain along with cough. In this study, prevalence of chest symptomatics among diabetes patients was found to be $10.6 \%$ in Udupi taluk. According to Table 3, more than $20 \%$ respondents who had total monthly family income; in the range of rupees 5000 to rupees 10000 , were chest symptomatics. More than $17 \%$ respondents, who had per capita income in the range of rupees 500 to rupees 1500 , were chest symptomatics. Out of the total subjects, $2 \%$ of 
Table 2

Distribution of respondents according to history of chest symptoms $(\mathrm{N}=25)$.

\begin{tabular}{lll}
\hline Chest symptoms present & $\begin{array}{l}\text { Yes } \\
\text { N (\%) }\end{array}$ & $\begin{array}{l}\text { No } \\
\text { N (\%) }\end{array}$ \\
\hline Cough associated with sputum & $11(44)$ & $14(56)$ \\
Cough associated with chest pain & $5(20)$ & $20(80)$ \\
Cough associated with fever & $1(4)$ & $24(96)$ \\
Cough associated with hemoptysis & $1(4)$ & $24(96)$ \\
\hline
\end{tabular}

$\mathrm{N}=$ Number

Table 3

Distribution of respondents according to chest symptomatics with respect to total monthly income (Rs) and per capita income (Rs), History of intermittent cough, history of TB, family history of DM, family history of TB, duration of diabetes (years), current smokers, duration of smoking (years), alcohol consumption, duration of alcohol consumption respectively. $(\mathrm{N}=132)$.

\begin{tabular}{|c|c|c|c|c|}
\hline \multirow[t]{2}{*}{ Variables } & & \multicolumn{2}{|c|}{ Chest symptomatics } & \multirow[t]{2}{*}{$p$ value } \\
\hline & & $\begin{array}{l}\text { Yes } \\
\text { N (\%) }\end{array}$ & $\begin{array}{l}\text { No } \\
\text { N (\%) }\end{array}$ & \\
\hline \multirow{3}{*}{$\begin{array}{l}\text { Total monthly family } \\
\text { income (Rs) }\end{array}$} & $<5000$ & $4(5.1)$ & 75 (94.9) & \multirow[t]{3}{*}{$0.028^{\mathrm{a}}$} \\
\hline & $5000-10000$ & $8(20.5)$ & $31(79.5)$ & \\
\hline & $>10000$ & $2(14.3)$ & $12(85.7)$ & \\
\hline \multirow[t]{3}{*}{ Per capita income (Rs) } & $<500$ & $1(2)$ & $49(98)$ & \multirow[t]{3}{*}{$0.023^{\mathrm{a}}$} \\
\hline & $500-1500$ & $11(17.7)$ & $51(82.3)$ & \\
\hline & $>1500$ & $2(10)$ & $18(90)$ & \\
\hline \multirow{2}{*}{$\begin{array}{l}\text { History of intermittent } \\
\text { cough }\end{array}$} & yes & $13(41.9)$ & $18(51.1)$ & \multirow[t]{2}{*}{$<0.0001^{\mathrm{a}}$} \\
\hline & no & $1(1)$ & 100 (99) & \\
\hline \multirow[t]{2}{*}{ History of TB } & yes & $4(36.4)$ & $7(63.6)$ & \multirow[t]{2}{*}{$0.017^{\mathrm{a}}$} \\
\hline & no & $10(8.3)$ & $111(91.7)$ & \\
\hline \multirow[t]{2}{*}{ Family history of DM } & yes & $2(4.3))$ & $45(95.7)$ & \multirow[t]{2}{*}{0.137} \\
\hline & no & $12(14.1)$ & $73(85.9)$ & \\
\hline \multirow[t]{2}{*}{ Family history of TB } & yes & $2(28.6)$ & $5(71.4)$ & \multirow[t]{2}{*}{0.161} \\
\hline & no & $12(9.6)$ & $113(90.4)$ & \\
\hline \multirow[t]{3}{*}{ Duration of diabetes (years) } & $0-2$ & $3(6.7)$ & $42(93.3)$ & \multirow[t]{3}{*}{0.530} \\
\hline & $2.1-5$ & $6(13.6)$ & $38(86.4)$ & \\
\hline & $>5$ & $5(11.6)$ & $38(88.4)$ & \\
\hline \multirow[t]{2}{*}{ Current smokers } & yes & $3(16.7)$ & $15(83.3)$ & \multirow[t]{2}{*}{0.407} \\
\hline & no & $11(9.6)$ & 103(90.4) & \\
\hline \multirow{3}{*}{$\begin{array}{l}\text { Duration of smoking (years) } \\
\qquad(\mathrm{N}=23)\end{array}$} & $0-10$ & $0(0)$ & $3(100)$ & \multirow[t]{3}{*}{0.616} \\
\hline & $11-25$ & $1(33.3)$ & $2(66.7)$ & \\
\hline & $>25$ & $2(11.8)$ & $15(88.2)$ & \\
\hline \multirow[t]{2}{*}{ Alcohol consumption } & yes & $6(20.7)$ & $23(79.3)$ & \multirow[t]{2}{*}{0.080} \\
\hline & no & $8(7.8)$ & $95(92.2)$ & \\
\hline \multirow{3}{*}{$\begin{array}{l}\text { Duration of alcohol } \\
\text { consumption (years) } \\
(\mathrm{N}=35)\end{array}$} & $\leq 10$ & $1(12.5)$ & $7(87.5)$ & \multirow[t]{3}{*}{1.000} \\
\hline & $11-25$ & $2(22.2)$ & $7(77.8)$ & \\
\hline & $>25$ & $3(16.7)$ & $15(83.3)$ & \\
\hline
\end{tabular}

$\mathrm{N}=$ Number

a Statistically Significant.

the subjects; having monthly per capita income less than Rs 500, reported chest symptoms. It can be seen from the Table 3, that approximately $42 \%$ respondents having history of intermittent cough were found to be chest symptomatics. More than $36 \%$ respondents, who had previous history of $\mathrm{TB}$, reported chest symptoms. It is also seen, that $4.3 \%$ of the respondents with family history of diabetes mellitus, were found as chest symptomatics of TB and $28.6 \%$ of the subjects having family history of TB were found to be chest symptomatics of TB. Both factors, family history of DM $(p=0.137)$ and family history of TB ( $p=0.161$ ) were not found to be much significant respectively.

Comparatively, during first five years from onset of diabetes mellitus, chest symptomatics were almost double than they were found during more than five years of period after diabetes onset. It was reported that; duration of diabetes $(p=0.530)$ was not significant with chest symptomatics, in this study. From Table 3, it is seen that $16.7 \%$ of the total smokers reported chest symptoms related to TB. Current smokers $(p=0.407)$ and duration of alcohol $(p=0.616)$ both were not found significant with chest symptomatics.

Distribution of chest symptomatics with respect to alcohol consumption and duration of alcohol consumption is shown in the Table 3 . About $20.7 \%$ of the alcoholics were found to be chest symptomatics. Respondents smoked for more than 10 years have made large contribution among chest symptomatics. Approximately $22.2 \%$ of the alcoholic respondents with drinking habit for 11-25 years, admitted having cough for two or more than two weeks. Alcohol consumption $(p=0.080)$ and duration of alcohol consumption $(p=1.000)$ didn't show any significant association with chest symptomatics.

\section{Discussion}

The study comprises of the age group of 18 years and above. In the study, the prevalence of chest symptomatics among diabetes patients in Udupi taluk was found to be $10.6 \%$. The comparison will help to point out the strength and weakness inherent; in the current study. Looking back, a study done in US highlighted the importance of including the subjects more than 40 years, who have tendency to complicate with TB. ${ }^{18}$ In another study in Pakistan, $82 \%$ patients were in the middle age group (40-70 years) ${ }^{19}$ Moreover, Patel et al. ${ }^{20}$ stated that $57 \%$ of the study subjects of his study, belonged to $40-60$ years age group. Ibrahim KK et al. ${ }^{9}$ reported that more than half of the subjects in his study were belonging to $40-60$ years age group (64\%). Hamid Ullah et al. ${ }^{21}$ explained that all patients having TB were older than 40 years. In comparison with all these studies, in current study; more than half of the respondents were belonged to 50-70 years age group.

Male participation was more than half of the total respondents in the current study (51.5\%). Around 64 females contributed in the current study. In contrast, female's contribution was only around $20 \%$ in the study done in Iraq $^{9}$

Study population consisted of 80\% NIDDM, 9\% IDDM (Insulin Dependent Diabetes Mellitus) and $11 \%$ diet-controlled subjects as stated by Jabbar et al. ${ }^{22}$ This quite corresponds with current study. In this study, among all respondents, $32.6 \%$ of respondents had history of diabetes since more than five years. In the converse of that, $51 \%$ study subjects had history of diabetes mellitus for more than 10 years duration till diagnosis of tuberculosis. ${ }^{22}$ According to Ibrahim KK et al., ${ }^{9}$ in their study; $32 \%$ subjects were having TB from zero to five years from the onset of diabetes. Another study revealed that around $56 \%$ of the total subjects had cough. ${ }^{19}$ Hamid U et al. ${ }^{21}$ revealed that fever (93\%) contributed to the major symptoms of TB in their study; Cough (45\%) and cough associated with sputum (29\%) were partly instrumental for TB. According to Jabbar et al., ${ }^{22}$ fever $(72 \%)$ and cough $(66 \%)$ represented the chest symptoms. In comparison with that, in our study, $21.2 \%$ of the respondents were found to be having cough. Only one person reported that he was having fever at the time of interview (4\%) and same proportion of patients (4\%) reported to be having haemoptysis. $\mathrm{P}$ value was $<0.0001$ for haemoptysis as well as for chest pain in the study by Ramdevrajani B et al. ${ }^{23}$ which is not significant in our study. About $36.8 \%$ diabetic tuberculosis patients had no symptoms. Therefore diagnosis was made with the help of radiological examination. ${ }^{24}$ Case series by Deshmukh et al. reported that $43.4 \%$ of TB patients had history of diabetes mellitus in their study ${ }^{1}$ Prevalence of TB among DM patients was found as $11.9 \% .{ }^{22}$ Whereas, according to one of the study done in Pakistan, prevalence of TB among DM patients was estimated as $14 \% .{ }^{19}$ Another study done in Imphal, India; estimated the prevalence of tuberculosis among DM patients with the help of radiological diagnosis as $27 \% .{ }^{9}$ In a previous study, Holden and Hitz explicated that out of 106 patients, 48 patients had diabetes before appearing TB. ${ }^{2}$ Among 380 diabetes patients, 121 patients (30.2\%) had co-morbid infections. Among them, one fifth of those infections were due to pulmonary TB. ${ }^{21}$

Total monthly family income $(p=0.028)$ and per capita income $(p=0.023)$ were found statistically significant with chest symptomatics respectively. Around $75 \%$ of the total respondents were having monthly family income less than Rs 5000 in our study. Previous study done in Peshawar, reported less proportion of low socio-economic class 
(54\%). ${ }^{21}$ The study done by Ibrahim KK et al. ${ }^{9}$ showed that $24 \%$ of the total subjects in their study had previous history of TB at some point in their life, which can be considered in a higher extent. The factors, history of intermittent cough $(p<0.0001)$ and history of TB ( $p=0.017$ ) were found to be significant with chest symptomatics respectively in our study. Apart from this, Webb EA et al. ${ }^{25}$ reported that, contact with TB case was a significant risk factor for developing TB disease $(p<0.002)$ in their study. This factor was not found to be significant in our study. Previous study in Pakistan showed that, highest prevalence of ТВ $(42.8 \%)$ was estimated among the patients having duration of diabetes more than 10 years ${ }^{19}$ Contradicting with this, in a Turkish study, within first five year after diagnosis of diabetes mellitus, proportion of patients developing TB was maximum (38\%) ${ }^{24}$ According to Ibrahim KK et al., ${ }^{9}$ in their study; $32 \%$ subjects were having TB from zero to five years from the onset of diabetes. Equating with this, in our study; it was seen that, $13.6 \%$ of the respondents who suffered from diabetes for two to five years, were considered as chest symptomatics of TB.

Finally, it was concluded from the study that the poor socioeconomic conditions turned out to be the major factor, responsible for occurrence of chest symptoms. Apart from that, the respondents having age more than 60 years were more likely to get chest symptoms of TB. It was seen from the study that, within first five years after diagnosis of $\mathrm{DM}$, there was high propensity of getting chest symptoms of TB. It was optically discerned that; the respondents having history of TB and history of intermittent cough in the past, has a major role in predisposition to TB. It was also discovered that, tendency of smoking and alcohol for longer duration might lead to get chest symptoms among diabetics.

Study would have been more comprehensive if large number of subjects could have been included.

There is need of designing; feasible and cost effective integrated public health care approach, for bidirectional screening within primary health care system in India. It will direct diabetes patients for early diagnosis and treatment which will improve health outcomes Systematic screening of chest symptomatics in TB prevalent areas will help to reduce the burden of tuberculosis among diabetics. It will help the health system to tackle the dual epidemic wave of TB and diabetes.

\section{Conflicts of interest}

Authors declare no funding and no conflicts of interest.

\section{Acknowledgement}

It is a small initiative to provide the evidence on the link between diabetes and tuberculosis, which may endorse the global health policy on collaborative activities against dual burden. We express our deep sense of gratitude to all the participants involved in the study for their time and cooperation during the data collection. We also appreciate Prasanna School of Public Health, Manipal University, Manipal as well as District health and family welfare, Udupi for their extended support.

\section{Appendix A. Supplementary data}

Supplementary data to this article can be found online at https:// doi.org/10.1016/j.cegh.2019.06.010.

\section{References}

1. Sen T, Joshi SR, Udwadia ZF. Review article. Tuberculosis and diabetes mellitus: merging epidemics. JAPI. 2009 May 57:399-404.

2. Guptan A, Shah A. Tuberculosis and diabetes: an appraisal. Ind J Tub. 2000;47:3-8

3. International Diabetes Federation. . IDF Diabetes Atlas 2013 [internet] 2013 [cited Jan 22, 2014] Available from:. http://www.eatlas.idf.org.

4. Beagley J, Guariguata L, Weil C, Motala A. Global estimates of undiagnosed diabetes in adults. Diab Res Clin Pract. 2014;103:150-160.

5. Lönnroth Knut, Roglic Gojka, Harries Anthony D. Improving tuberculosis prevention and care through addressing the global diabetes epidemic: from evidence to policy and practice. Lancet Diabetes Endocrinol. 2014;2:730-739.

6. WHO Executive Board (2014). 134th session. Global strategy and targets for tuberculosis prevention, care and control after 2015. EB134.R4. Geneva: World Health Organization; 2014.

7. Young F, Critchley J, Unwin N. Diabetes \& tuberculosis: a dangerous liaison \& no white tiger. Indian J Med Res. 2009 July;130:1-4.

8. Sayed Sulaiman SA, Mohd Zain FA, Abdul Majid S, et al. Tuberculosis among diabetic patient. Webmed Cent Infect Dis. 2011;2(12).

9. Ibrahim KK. The relation between tuberculosis and diabetes mellitus in patients. $\mathrm{J}$ Kufa Univ Life Sci 3:1-11.

10. Qu Hui Qi, Rentfro AR, Lu Y, et al. Host susceptibility to tuberculosis: insights from a longitudinal study of gene expression in diabetes. Int $J$ Tuberc Lung Dis. 2012;16(3):370-372.

11. Van Crevel R, Alisjahbana B. More on tuberculosis. Lancet. 2008;371:647-648.

12. Revised National TB Control Programme Annual Status Report [internet]2013[cited 9/05/2019]. . Available from: https://tbcindia.gov.in/showfile.php?lid =3163.

13. Sullivan T, Ben Amor Y. The Co-management of tuberculosis and diabetes: challenges and opportunities in the developing world. PLoS Med. 2012;9:7.

14. Behera D. TB and Diabetes- the dual epidemic: is it a matter of concern? Indian $J$ Tuberc. 2011;58(4):143-147.

15. Angadi J. North Karnataka Focus of Survey on Diabetes, Bangalore [internet] 2012 [updated 2012Nov; Cited 29/06/2013]. . Available from: http://www.deccanherald. com/content/291784/north-karnataka-focus-survey-diabetes.html.

16. Balakrishnan S, Vijayan S, Nair S, et al. High diabetes Prevalence among tuberculosis Cases in Kerala, India. PLoS One. 2012;7(10).

17. Project concern International. A Person-Centered Approach to Disease Prevention [internet] [cited 14/07/13]. . Available from: http://www.pciglobal.org/mexico/.

18. Restrepo BI, Fisher-Hoch SP, Crespo JG, et al. Type 2 diabetes and tuberculosis in a dynamic binational border population. Epidemiol Infect. 2007;135:483-491.

19. Amin S, Khattak MI, Shabbier G, Wazir MN. Frequency of the pulmonary tuberculosis in patients with diabetes mellitus. Gomal J Med Sci. 2011 July-Dec;9(2):163-165.

20. Patel JC. Complications in 8793 cases of diabetes mellitus 14 years study in Bombay Hospital, Bombay, India. Ind J Med Sci. 1989 July;43(7):177-183.

21. ullah Hamid, Iqbal Z, Ullah Zia, Mahboob A, Masood-ur-Rehman. Frequency of pulmonary tuberculosis in patients presenting with diabetes. PJCM. 2009;15(4):1-7.

22. Jabbar A, Hussain SF, Khan AA. Clinical characteristics of pulmonary tuberculosis in adult Pakistani patients with co-existing diabetes mellitus. EMHJ. 2006;12(5):522-527

23. Ramdevrajani B, Ghani MH, Shah ZA, Ghori RA. Frequency of pulmonary tuberculosis in diabetes mellitus. Med Channel. Sept 2007;13(3):100.

24. Yurteri G, Sarac S, Orhan D, Ofluoglu H, Demiroz F. Features of pulmonary tuberculosis in patients with diabetes mellitus: a comparative study. Turk Respir J. 2004;5(1):5-8

25. Webb EA, Hesseling AC, Schaff $\mathrm{H}$, et al. High prevalence of mycobacterium tuberculosis infection and disease in children and adolescents with type 1 diabetes mellitus. Int J Tuberc Lung Dis. 2009;13(7):868-874. 